\title{
Prevention of Hepatitis B Virus and Hepatitis C Virus Transmission in Hemodialysis Centers: Review of Current International Recommendations
}

\author{
Sarra Elamin ${ }^{* 1}$ and Hasan Abu-Aisha ${ }^{2}$ \\ 1. Physician, Ahmed Gasim Kidney Transplant Center and Sudan Peritoneal Dialysis Program, Sudan \\ 2. Consultant Physician and Nephrologist, National Ribat University Hospital and Sudan Peritoneal Dialysis Program, Sudan
}

\begin{abstract}
Introduction: Hepatitis $\mathrm{B}$ virus (HBV) and hepatitis $\mathrm{C}$ virus (HCV) infections in hemodialysis (HD) patients are associated with adverse outcomes, especially after kidney transplantation.

Review: In the HD setting, cross-contamination to patients via environmental surfaces, supplies, equipment, multiple-dose medication vials and staff members is mainly responsible for both HBV and HCV transmission. The incidence and prevalence of HBV in HD centers have dropped markedly as a result of isolation strategy for HBsAg positive patients, the implementation of infection control measures and the introduction of HBV vaccine. The incidence and prevalence of $\mathrm{HCV}$ infection among HD patients remain higher than the corresponding general population. There is ongoing debate as to whether isolation of $\mathrm{HCV}$ infected patients is needed to combat high anti-HCV seroconversion rates. The current guidelines do not recommend isolation or the use of dedicated machines for $\mathrm{HCV}$ infected patients, and rely on strict adherence to infection control measures for the prevention of $\mathrm{HCV}$ transmission in the HD setting. Investigations of dialysis associated outbreaks of HCV infection indicate that transmission most likely occurs because of inadequate infection control practices. Routine screening of anti-HCV negative patients, with HCVantibody testing, and monthly monitoring of ALT levels is recommended to monitor transmission within centers.
\end{abstract}

Conclusion: Prevention of transmission of $\mathrm{HBV}$ and HCV in the HD setting warrants a multi-faceted approach. Not enough stress can be placed on the importance of adequate infection control practices for the prevention of both infections. Prevention of HBV transmission is augmented by correct implementation of isolation strategies and the universal vaccination of susceptible patients.

\footnotetext{
* Corresponding author; Sudan Peritoneal Dialysis Program, POB 363, Khartoum, Sudan.

E mail: sarraelamin@sudanpd.org
}

Keywords: Hemodialysis; Hepatitis B Virus; Hepatitis C Virus; Infection Control; Isolation

\section{The authors declared no conflict of interest}

\section{Introduction}

Chronic hemodialysis (HD) patients are at high risk for infection because the process of HD requires vascular access for prolonged periods and because of their immunosuppressed status. In an environment shared by multiple patients, there are repeated opportunities for transmission of infectious agents.

Surveillance for infections associated with chronic HD has always focused on viral hepatitis, particularly hepatitis $\mathrm{B}$ virus (HBV) and hepatitis $\mathrm{C}$ virus (HCV) infections. The mortality and morbidity of these infections in the dialysis population is difficult to quantify. Many patients with ESRD do not live long enough to develop the well known complications related to chronic viral hepatitis. Nevertheless, several reports were able to demonstrate that the presence of anti-HCV antibodies predicted increased mortality in the dialysis population $[1,2]$.

The negative impact on outcome after kidney transplantation is even more pronounced. In a report that evaluated the outcome of 542 kidney transplant recipients, $33 \%$ of whom were anti-HCV positive and $4 \%$ were $\mathrm{HBsAg}$ positive, both anti-HCV positive and HBsAg positive patients were found to have diminished patient survival. In addition, anti-HCV positivity was associated with diminished graft survival [3]. In a metaanalysis of six observational studies, HBsAg in serum was demonstrated to be an independent and significant risk factor for death and graft failure after renal transplantation compared to seronegative patients, with an estimated relative risk of 2.49 and 1.44, respectively [4]. A recently published analysis of the Australian and New Zealand Dialysis and Transplant registry found that 
Table 1: Estimated average risk of seroconversion following a percutaneous exposure to an infected source [8, 9]

\begin{tabular}{lc}
\hline Virus & Risk of seroconversion \\
\hline Hepatitis B Virus (HBsAg positive, HBeAg positive) & $19-30 \%$ \\
Hepatitis B Virus (HBsAg positive, HBeAg negative) & $5 \%$ \\
Hepatitis C Virus & $1.8 \%$ \\
Human Immunodefficiency Virus (HIV) & $0.3 \%$ \\
\hline
\end{tabular}

patient survival among anti-HCV positive and anti-HCV negative renal transplant recipients was $77 \%$ versus $90 \%$ and $50 \%$ versus $79 \%$ at 5 and 10 years, respectively. The adjusted hazards ratio for patient death was 2.38 , and the adjusted hazard ratio for graft loss was 1.7 for anti-HCV positive patients [2].

This review is intended to provide a concise but comprehensive description of the epidemiology and risk factors of both viral infections in HD patients, and to outline the current recommendations for their control and prevention.

\section{HBV infection in HD patients}

\section{Incidence and prevalence}

The world can be divided into three areas where the prevalence of chronic HBV infection is high $(>8 \%)$, intermediate $(2-8 \%)$, and low $(<2 \%)$. High endemicity areas include south-east Asia and the Pacific Basin (excluding Japan, Australia and New Zealand), subSaharan Africa, the Amazon Basin, parts of the Middle East, the central Asian Republics and some countries in Eastern Europe. In these areas, about $70-90 \%$ of the population become HBV infected before the age of 40 and $8-20 \%$ of people are HBV carriers. Low endemicity areas include North America, Western and Northern Europe, Australia and parts of South America. The carrier rate there is less than $2 \%$ and less than $20 \%$ of the population is infected with HBV. The rest of the world falls into the intermediate range of HBV prevalence, with $2-8 \%$ of a given population being HBV carriers [5]. While perinatal transmission or transmission during early childhood is responsible for the high rate of chronic infection in Asia and Africa, sexual or parenteral exposure account for most cases in industrialized countries [5].

HBV infection was quite common in HD facilities during their early years. However, the isolation strategy for HBsAg positive patients, the implementation of infection control measures, the discovery of erythropoietin, and the introduction of $\mathrm{HBV}$ vaccine have significantly reduced HBV infection rates in HD centers. In the United States, the incidence of newly acquired HBV infection among chronic HD patients was $6.2 \%$ in 1974 and declined to $0.06 \%$ by 1999 . Prevalence of chronic HBV infection also declined from $7.8 \%$ in 1976 to $0.9 \%$ by 1999 [6].

The Dialysis Outcomes and Practice Patterns Study (DOPPS) estimated HBV prevalence and incidence in a randomly selected sample from 308 representative dialysis facilities in France, Germany, Italy, Spain, the United Kingdom, Japan, and the United States. The adjusted HBV seroconversion rate was 0.4-1.8 seroconversions per 100 patient-years. The majority of surveyed HD facilities (78.1\%) had a seroconversion rate of zero conversions per 100 patient-years [7].

This probably explains why recently reported prevalence rates of HBV infection in HD facilities seem to concur more closely with its prevalence in the corresponding general population. In the DOPPS study, the mean HBV facility prevalence was $3.0 \%$ with a median of $1.9 \%$ [7]. These relatively low figures probably reflect the low prevalence of chronic HBV infection in these countries' general population. In contrast, a much higher prevalence rate of $\mathrm{HBV}$ infection among dialysis patients was reported from China (14.6\%), which belongs to $\mathrm{HBV}$ high endemicity areas [1].

\section{Transmission}

HBV is transmitted by exposure to infectious blood or body fluids that contain blood through a skin puncture or by direct contact with mucous membranes. HBV is highly infectious compared with other blood-borne viruses; an untreated percutaneous exposure to an infected source carries a risk of seroconversion of up to $30 \%$ (Table 1) [8].

All hepatitis B surface antigen ( $\mathrm{HBsAg}$ ) positive persons are infectious, but those who are also positive for hepatitis $\mathrm{B}$ e antigen ( $\mathrm{HBeAg}$ ) circulate $\mathrm{HBV}$ at high titers in their blood and are potentially more infectious [10]. Furthermore, HBV at high titers can be present on environmental surfaces in the absence of any visible blood and still result in transmission. It is relatively stable in the environment and remains viable for at least 7 days at room temperature [11]. In HD centers, HBsAg has been detected on clamps, scissors, dialysis machine control 
Table 2: Significance of HBV serological markers

\begin{tabular}{|c|c|c|}
\hline Name & Description & Significance \\
\hline HBsAg & HBV surface antigen & $\begin{array}{l}\text { Appears } 30-60 \text { days after exposure }{ }^{*} \text { and persists for variable periods } \\
\text { Persists in chronic HBV infection } \\
\text { Indicates that the patient is infective }\end{array}$ \\
\hline $\mathrm{HBeAg}$ & HBV e antigen & $\begin{array}{l}\text { Sometimes present in acute HBV infecton } \\
\text { Sometmes present in chronic HBV infection } \\
\text { Indicates that the patient is highly infective }\end{array}$ \\
\hline Anti-HBs & Antibody to HBV surface antigen & $\begin{array}{l}\text { Appears after recovery from HBV infection } \\
\text { Appears after successful vaccination against HBV } \\
\text { Indicates immunity against HBV }\end{array}$ \\
\hline Total anti-HBc & $\begin{array}{l}\text { Antibody to HBV core antigen } \\
\text { (IgG and IgM subtypes) }\end{array}$ & $\begin{array}{l}\text { Appears during acute HBV infection } \\
\text { Persists for life } \\
\text { Indicates previous exposure to HBV }\end{array}$ \\
\hline IgM anti-HBc & $\begin{array}{l}\text { Antibody to HBV core antigen } \\
\text { (IgM subtype only) }\end{array}$ & $\begin{array}{l}\text { Appears during acute HBV infection } \\
\text { Persists for approximately } 6 \text { months } \\
\text { Indicates recent HBV infection (within } 6 \text { months) }\end{array}$ \\
\hline
\end{tabular}

* Transient HBsAg positivity (up to 18 days) can be detected in some patients during vaccination [17]

knobs, and doorknobs [12]. Cross-contamination to patients via environmental surfaces, supplies, equipment, multiple dose medication vials and staff members plays the prime role in HBV transmission in this setting [6].

Once the factors that promote HBV transmission within HD centers were identified, recommendations for the prevention of this transmission were made available. The Rosenheim Report was published in UK in 1972 and the Center for Disease Control and Prevention (CDC) recommendations were published in the USA in 1977 $[13,14]$. The implementation of these guidelines had a remarkable effect on the incidence and prevalence of $\mathrm{HBV}$ in HD centers. Investigations of outbreaks of HBV infection that occur in chronic HD centers almost always document failure to use recommended infection control practices [6].

\section{Clinical features and natural history}

HBV causes both acute and chronic hepatitis. In adults with normal immune status, most (94-98\%) recover completely from newly acquired HBV infections, eliminating the virus from the blood and producing neutralizing antibodies that create immunity from future infection with all subtypes of the virus. In immunosuppressed persons (including HD patients), most newly acquired HBV infections result in chronic infection [15].

\section{Screening and diagnostic tests}

$\mathrm{HBV}$ infection is associated with a number of serological markers that are present during different stages of the infection (Tables 2 and 3) $[5,16]$.
In some persons, the only HBV serologic marker detected is anti-HBc. In most persons with isolated anti-HBc, the result appears to be a false positive, and a primary anti-HBs response develops after a three-dose series of hepatitis B vaccine [18]. In a small percentage of isolated anti-HBc cases, HBV DNA is detectable in serum and the person is considered to have occult HBV infection. These persons are unlikely to be infectious to others except under unusual circumstances involving direct percutaneous exposure to large quantities of blood (e.g. blood transfusion) [18].

The prevalence of isolated anti-HBc among HD patients varies between $6.2-35 \%$ in different reports, and the reported prevalence of detectable HBV DNA in the serum of such patients also varies between 0-50\% [19-21]. The Center for Disease Control and Preventions has set recommendations for the management HD patients with isolated anti-HBc (Figure 1) [6]. The same guidelines consider isolation for such patients unnecessary because they are HBsAg negative [6].

\section{Prevention of HBV transmission in the HD setting}

The segregation of HBsAg positive patients and their equipment from HBV susceptible patients is estimated to have resulted in $70-80 \%$ reduction in the incidence of HBV infection among HD patients [6]. The success of isolation practices in preventing transmission of $\mathrm{HBV}$ infection is linked to other infection control practices, including routine serological surveillance and routine cleaning and disinfection. Vaccination of all susceptible patients and the avoidance of blood transfusions have 
Table 3: Interpretation of HBV serological markers

\begin{tabular}{|c|c|c|c|c|}
\hline HBsAg & Anti-HBs & $\begin{array}{l}\text { Total } \\
\text { anti-HBc }\end{array}$ & $\begin{array}{l}\text { IgM } \\
\text { anti-HBc }\end{array}$ & Interpretation \\
\hline- & - & - & - & $\begin{array}{l}\text { No previous exposure to HBV infection } \\
\text { No vaccination (or unsuccessful vaccination) against HBV } \\
\text { Patient is susceptible to HBV infection }\end{array}$ \\
\hline+ & - & - & - & $\begin{array}{l}\text { Early acute HBV infection } \\
\text { Infectivity is high in case of concomitantly positive } \mathrm{HBeAg} \\
\text { Patient is infective }\end{array}$ \\
\hline+ & $-1+$ & + & + & $\begin{array}{l}\text { Acute HBV infection } \\
\text { Appearance of anti-HBs indicates resolving infection } \\
\text { Patient is infective }\end{array}$ \\
\hline+ & - & + & - & $\begin{array}{l}\text { Chronic HBV infection } \\
\text { Infectivity is high in case of concomitantly positive } \mathrm{HBeAg} \\
\text { Patient is infective }\end{array}$ \\
\hline- & + & + & - & $\begin{array}{l}\text { Recovery from previous HBV infection } \\
\text { Patient is immune against HBV }\end{array}$ \\
\hline- & + & - & - & $\begin{array}{l}\text { Successful vaccination against HBV } \\
\text { Patient is immune against HBV }\end{array}$ \\
\hline- & - & + & - & $\begin{array}{l}\text { Possibilities include past HBV infection with failed or waning immune } \\
\text { response, acute HBV infection during convalescence, low level of } \\
\text { chronic HBV infection, or false positive reaction }\end{array}$ \\
\hline
\end{tabular}

also played an important role in minimization HBV transmission in the HD population.

\section{Hepatitis $B$ vaccine}

Hepatitis B vaccine has been available since 1982 and is the first and currently the only vaccine against a major human cancer. Vaccines are produced by two different methods, plasma derived or recombinant DNA, both of which have an outstanding record of safety and efficacy [5].

The preferred schedule for routine pre-exposure prophylaxis consists of three injections at 0,1 , and 6 months. In cases of post-exposure prophylaxis, an alternative schedule of four injections at $0,1,2$, and 12 months is preferred [5]. For dialysis patients, another four-injection schedule at $0,1,2$, and 6 months is recommended (Engerix- $\mathrm{B}^{\circledR}$ ), with a higher dose of 40 mcg per injection $[5,6]$.

All doses should be given by intramuscular injection in the deltoid muscle. The course of vaccination should not be started over when a scheduled dose is missed or postponed, but should be completed in due course. Hepatitis B vaccination does no harm to $\mathrm{HBV}$-immune or HBV-infected individuals. There is no recommendation for the routine administration of booster doses [5]. If a lower than recommended vaccine dose is administered to dialysis patients, the dose should be repeated [6].

To evaluate response, anti-HBs titer should be measured for all vaccinated persons 1-2 months after the last vaccine dose. An initial anti-HBs titer of $\geq 10 \mathrm{mIU} / 1$ is regarded protective [5]. Vaccinees who do not respond to the basic immunization doses should be offered one or two additional injections of vaccine [5]. Persistent non-responders should be screened for HBsAg. Nonresponders who are HBsAg negative should be warned to seek post-exposure prophylaxis in the event of contact with potentially infectious blood [6].

The recommended primary series of hepatitis B vaccine induces a protective anti-HBs response in $90-95 \%$ of adults with normal immune status [5]. The proportion of HD patients who develop a protective antibody response after vaccination (even with higher dosages) is lower, with a median of $64 \%$ for the three-dose schedule and $86 \%$ for the four-dose schedule [6]. Higher antibody response rates could be achieved by vaccinating patients with chronic renal failure before they become dialysis dependent [22].

Among persons with normal immune status who respond to the primary series of hepatitis $B$ vaccine, protection against $\mathrm{HBV}$ is virtually complete and persists even when antibody titers become undetectable [6]. On the 
Figure 1: Outline of the management of HD patients with isolated anti-HBc

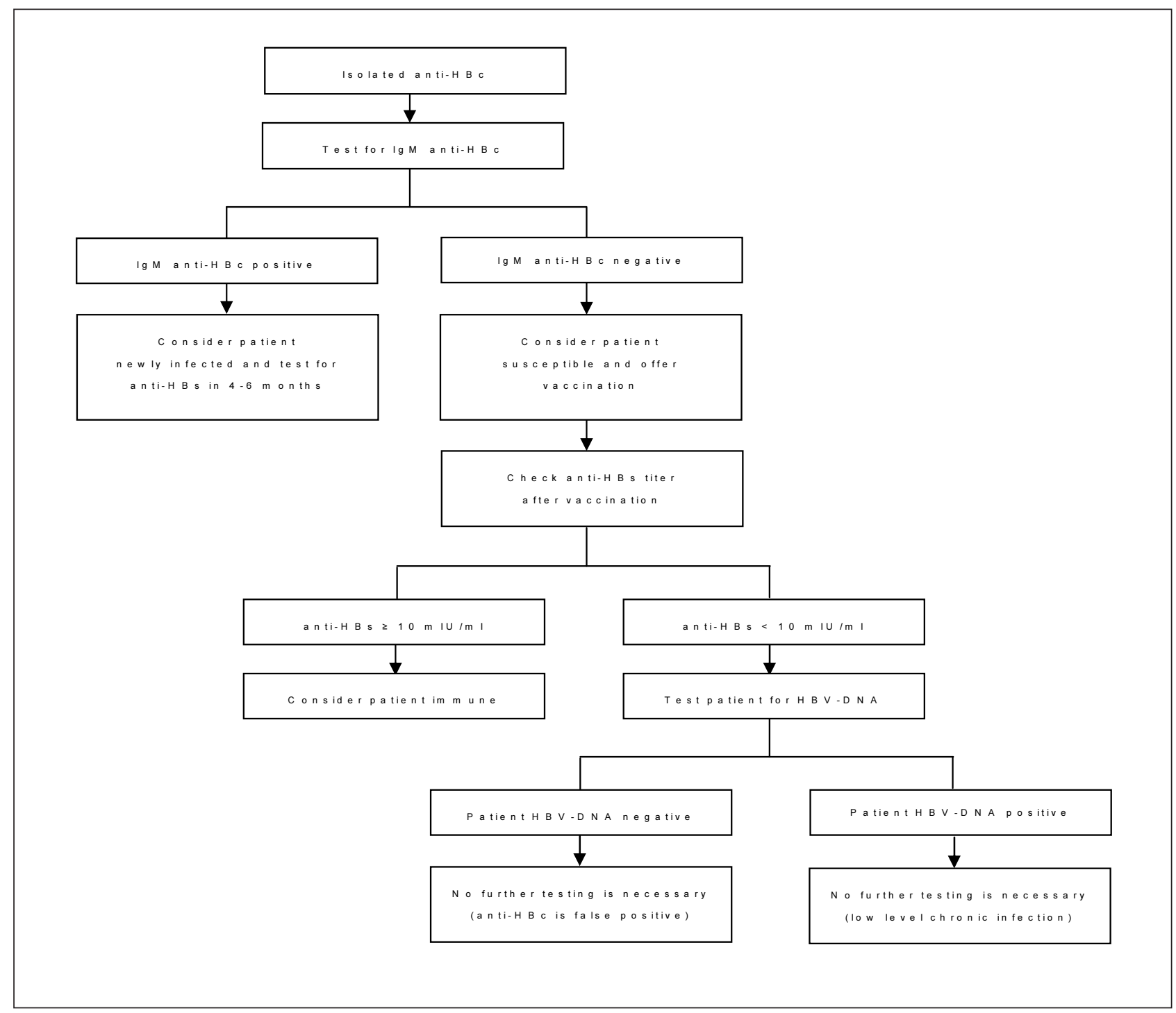

other hand, vaccination of HD patients reduces the risk of $\mathrm{HBV}$ infection by $70 \%$ [23]. No HBV infections have been reported among vaccinated HD patients who maintained protective levels of anti-HBs, but protection is not maintained when antibody titers fall below protective levels [24]. Immunized HD patients whose antibody titers subsequently declined below protective levels virtually always respond to a booster dose of the vaccine [25].

\section{Post-exposure prophylaxis against HBV}

In case of contamination with blood or body fluids from a potentially infected source, it is recommended to wash the skin with soap and water and irrigate the eyes and mucous membrane [26]. Base line HBV, HCV and HIV status of the exposed person and the source patient should be made available. If the source patient is not available or refuses testing, consider him/her infected [26].

The management of a possible occupational exposure to HBV differs according to the susceptibility of the exposed person. For susceptible persons, postexposure prophylaxis should include both hepatitis B immunoglobulin (HBIG) and hepatitis $B$ vaccine if the source patient is $\mathrm{HBsAg}$ positive, unidentifiable, or refuses testing (Table 4).

If the source patient is known to be HBsAg negative, HBIG is not indicated but hepatitis B vaccine should be administered following the same guidelines. This management does not differ in case of pregnancy [26]. 
Table 4: recommended post-exposure prophylaxis if the source patient is HBsAg positive, unidentifiable, or refuses testing ${ }^{*}$ [26]

\begin{tabular}{|c|c|}
\hline Status of exposed person & Recommended action \\
\hline $\begin{array}{l}\text { Fully vaccinated } \\
\text { with documented antibody response }\end{array}$ & $\begin{array}{l}\text { If previously documented anti-HBs } \geq 10 \mathrm{mIU} / \mathrm{ml} \text { : } \\
\text { - The exposed subject is virtually immune } \\
\text { - No need for HBIG or booster dose of vaccine }\end{array}$ \\
\hline $\begin{array}{l}\text { Fully vaccinated } \\
\text { with no documented antibody response }\end{array}$ & $\begin{array}{l}\text { Check anti-HBs titer. If anti-HBs } \geq 10 \mathrm{mIU} / \mathrm{ml} \text { no further action is required; otherwise: } \\
\text { - Give } \mathrm{HBIG}(0.06 \mathrm{ml} / \mathrm{kg}) \\
\text { - Give booster dose of hepatitis B vaccine }\end{array}$ \\
\hline $\begin{array}{l}\text { Certain of receiving } \\
1-2 \text { doses of hepatitis } B \text { vaccine }\end{array}$ & $\begin{array}{l}\text { Check anti-HBs titer. If anti-HBs } \geq 10 \mathrm{mIU} / \mathrm{ml} \text { no further action is required; otherwise: } \\
\text { - Give HBIG }(0.06 \mathrm{ml} / \mathrm{kg}) \\
\text { - Complete vaccination or restart accelerated schedule }(0,1,2,12 \text { months })\end{array}$ \\
\hline $\begin{array}{l}\text { Did not receive } \\
\text { any dose of hepatitis } B \text { vaccine }\end{array}$ & $\begin{array}{l}\text { Check anti-HBs titer. If anti-HBs } \geq 10 \mathrm{mIU} / \mathrm{ml} \text { no further action is required; otherwise: } \\
\text { - Give HBIG }(0.06 \mathrm{ml} / \mathrm{kg}) \text { and repeat dose after one month } \\
\text { - Start hepatitis B vaccination according to accelerated schedule }(0,1,2,12 \text { months })\end{array}$ \\
\hline $\begin{array}{l}\text { Fully vaccinated } \\
\text { and documented non-responder }\end{array}$ & $\begin{array}{l}\text { If previously documented anti-HBs }<10 \mathrm{mIU} / \mathrm{ml} \text { : } \\
\text { - Give HBIG }(0.06 \mathrm{ml} / \mathrm{kg}) \text { and repeat dose after one month } \\
\text { - Start hepatitis B vaccination according to accelerated schedule }(0,1,2,12 \text { months })\end{array}$ \\
\hline $\begin{array}{l}\text { Received } 4 \text { or more doses of vaccine } \\
\text { and documented non-responder }\end{array}$ & $\begin{array}{l}\text { If previously documented anti-HBs }<10 \mathrm{mIU} / \mathrm{ml} \text { : } \\
\text { - Give HBIG }(0.06 \mathrm{ml} / \mathrm{kg}) \text { and repeat dose after one month } \\
\text { - Consider alternative hepatitis B vaccine }\end{array}$ \\
\hline
\end{tabular}

* If the source patient is known to be HBsAg negative, management would follow the same guidelines with the exclusion of HBIG

HBIG and hepatitis B vaccine should always be given at different sites. When indicated, HBIG and the first dose of the vaccine must be administered as soon as possible, preferably within 24 hours from the exposure and no later than one week. Serological follow-up is not recommended recommended when post-exposure management is in accord with these recommendations [26].

\section{$\mathrm{HCV}$ infection in HD patients}

\section{Incidence and prevalence}

In 1989, the virus responsible for most cases of non-A non-B hepatitis was identified and named hepatitis $\mathrm{C}$ virus (HCV). The World Health Organization (WHO) estimates that the global prevalence of $\mathrm{HCV}$ infection averages $3 \%$, or around 170 million infected persons worldwide. Prevalence of confirmed anti-HCV positivity in blood donors ranges from less than $0.1 \%$ in Northern Europe to $0.1-0.5 \%$ in Western Europe, North America, parts of Central and South America, Australia, and a few regions of Africa. Intermediate rates (1-5\%) have been reported from Brazil, Eastern Europe, the Mediterranean area, the Indian subcontinent, and parts of Africa and Asia [27]. The estimated prevalence of HCV infection among HD patients is much higher. Moreover, the prevalence of $\mathrm{HCV}$ in HD patients does not seem to reflect its prevalence in the corresponding general population.

Seven years ago, the DOPPS study estimated the mean prevalence of HCV among adult HD patients in France, Germany, Italy, Japan, Spain, the United Kingdom, and the United States to be $13.5 \%$, varying between countries from $2.6 \%$ to $22.9 \%$ [28]. The mean prevalence of $\mathrm{HCV}$ infection among HD patients in Asia-Pacific countries was recently reported to be $7.9 \% \pm 5.5 \%$. The prevalence was less than $5 \%$ in Australia/New Zealand, Korea, Japan and Thailand, between $5-15 \%$ in Hong Kong, Taiwan and Malaysia, and more than $15 \%$ in China [1]. The prevalences of HCV infection observed in dialysis patients in these countries were considerably higher than those in the corresponding general populations (range $1.0-2.9 \%$ ) [29].

In the DOPPS study, the adjusted HCV seroconversion rate was 1.2-3.9 seroconversions per 100 patient-years, and more than half the facilities had no documented seroconversions [28].

\section{Transmission}

$\mathrm{HCV}$ is most efficiently transmitted by direct percutaneous exposure to infectious blood, and like HBV, the chronically infected person is central to the epidemiology 
of $\mathrm{HCV}$ transmission. Percutaneous exposure to an infected source carries a risk of seroconversion of $1.8 \%$ for HCV [9].

In the HD setting, cross-contamination to patients via environmental surfaces, supplies, equipment, multiple dose medication vials and staff members is mainly responsible for $\mathrm{HCV}$ transmission [6]. In one South American study, HD treatment (but not blood transfusion) was the only risk factor significantly associated with $\mathrm{HCV}$ infection in ESRD patients, with a hazard ratio of 5.7 compared to 22.3 for HBV infection [30]. In the USA, several reports since 1990 estimated the annual rate of anti-HCV seroconversion to be $0.7-3 \%$ among HD patients; none of the patients who seroconverted had received transfusions in the interim or were injecting-drug users [6]. Investigations of dialysis associated outbreaks of $\mathrm{HCV}$ infection indicate that transmission most likely occurs because of inadequate infection control practices $[6,31]$.

\section{Clinical features and natural history}

HCV causes both acute and chronic hepatitis. The incubation period ranges from 14-180 days. Persons with newly acquired (acute) HCV infection typically are either asymptomatic or have a mild clinical illness. After acute $\mathrm{HCV}$ infection, chronic HCV infection develops in most infected persons (75-85\%). Of persons with chronic $\mathrm{HCV}$ infection, $60-70 \%$ have persistent or fluctuating ALT elevations, indicating active liver disease [32]. Although similar rates of chronic liver disease have been observed among HCV-infected chronic HD patients (based on liver biopsy results), these patients might be less likely to have biochemical evidence of active liver disease [33].

\section{Screening and diagnostic tests}

$\mathrm{HCV}$ infection is mainly diagnosed by tests that measure anti-HCV, most commonly enzyme immunoassays (EIAs). The average time from exposure to seroconversion is $8-9$ weeks [34]. Anti-HCV can be detected in $80 \%$ of patients within 15 weeks after exposure and in $>97 \%$ within 6 months [6]. These tests do not distinguish between acute, chronic, or resolved infection. Anti-HCV persists indefinitely in most persons, but does not protect against re-infection [6].

Most HD patients (average: 94\%) with newly acquired HCV infection have elevated serum ALT levels [6], and this elevations often precede anti-HCV seroconversion. Compared with ALT, AST is a less specific indicator of HCV-related liver disease among HD patients. Monthly monitoring of ALT levels in HD patients is used to facilitate early detection of newly acquired HCV infection.
The diagnosis of $\mathrm{HCV}$ infection also can be made by qualitatively detecting HCV-RNA using gene amplification techniques (e.g. RT-PCR). HCV-RNA can be detected in serum or plasma within 1-2 weeks after exposure, well before the onset of ALT elevations or the appearance of anti-HCV. In rare instances, detection of HCV RNA might be the only evidence of $\mathrm{HCV}$ infection [6]. Some HCV infected persons might be only intermittently HCV RNA positive, particularly those with acute hepatitis $\mathrm{C}$ or with end-stage liver disease caused by hepatitis $\mathrm{C}$.

The CDC guidelines do not recommend using RT-PCR for HCV-RNA as the primary test for routine screening of HD patients [6]. According to the CDC, patients should be screened by EIA to test for anti-HCV. Positive results should then be confirmed by HCV-RNA testing. The CDC guidelines also rely on more frequent EIA testing to detect new HCV infections following cases of suspected nosocomial transmission [6].

In contrast, the KDIGO guidelines advice HD units with a high prevalence of $\mathrm{HCV}$ infection to consider nucleic acid tests for initial testing of patients when they first start HD or when they transfer from another HD facility. According to the same guidelines, nucleic acid tests should be performed in all patients who may have been exposed if a new HCV infection in a HD unit is suspected to be nosocomial. In addition, repetition of nucleic acid tests is recommended within 2-12 weeks in initially negative patients [31].

Both guidelines consider retesting with EIA every 6-12 months to be sufficient for surveillance of chronic HD patients. Both guidelines recommend nucleic acid testing for HD patients with unexplained elevations in aminotransferase levels if anti-HCV is repeatedly negative $[6,31]$.

\section{Prevention of HCV transmission in the HD setting}

The Center for Disease Control and Prevention (CDC) [6] and Kidney Disease Improving Global Outcomes (KDIGO) [31] guidelines do not recommend isolation of $\mathrm{HCV}$ infected patients as an alternative to strict infectioncontrol measures, nor the use of dedicated dialysis machines for $\mathrm{HCV}$ infected patients.

$\mathrm{HCV}$ does not cross intact dialyzer membranes. In the event of a membrane leak, transmission would require $\mathrm{HCV}$ to reach fresh dialysate used for a subsequent patient and enter the blood compartment for that patient through back-filtration across the dialyzer membrane. This theoretical mechanism is considered highly improbable in single-pass machines $[6,31]$. 
Investigations of dialysis associated outbreaks of $\mathrm{HCV}$ infection indicate that transmission most likely occurs because of inadequate infection control practices. The majority of investigations were able to discount transmission via the internal pathways of the dialysis machine easily as the patients involved in the outbreak were dialyzed at the same time and/or on separate machines. Several of these reports documented nosocomial HCV transmission despite the existence of isolation procedures for HCV infected patients [6, 31].

Several investigators reported that dialyzing anti-HCV positive patients on dedicated machines was associated with a lower HCV seroconversion rate, including a randomized multicenter study $[35,36]$. However, HCV seroconversion was not eliminated by this approach, and deviations from the CDC guidelines on hygienic precautions were not accounted for. In contrast, there are reports in which $\mathrm{HCV}$ transmission was reduced by reinforcement of basic hygienic precautions without any isolation measures [37, 38]. Additionally, two large studies, one of which is the DOPPS study, found that after adjusting for potential confounders, isolation does not protect against HCV transmission in HD patients [28, 39].

It is noteworthy that the "isolation" referred to by most of these investigators actually means dialyzing anti-HCV positive patients on dedicated machines by the same staff in the same dialysis ward as anti-HCV negative patients. This may seem odd since available evidence suggests that the nosocomial transmission of $\mathrm{HCV}$ in $\mathrm{HD}$ units occurs as a result of environmental contamination rather than through the internal pathway of the HD machines.

This mode of transmission has been combated in case of HBV through the implementation of strict isolation strategies. Despite the fact that $\mathrm{HBV}$ is ten times more infectious than $\mathrm{HCV}$, its transmission in the HD ward has been rendered almost negligible in units that adhere to the CDC guidelines of segregating HBV infected patients along with their equipment and staff in separate rooms. The CDC guidelines for $\mathrm{HCV}$ infected patients were not as successful in reducing the prevalence of $\mathrm{HCV}$ infection.

The DOPPS study estimates the prevalence of HBV infection in HD patients in the USA at $2.4 \%$, with an adjusted incidence of 0.4 seroconversions per 100 patientyears [7]. The same study estimates the prevalence of $\mathrm{HCV}$ infection in HD patients in the USA at $14 \%$, with an adjusted incidence of 2.5 seroconversions per 100 patient-years [28].

An interesting report from a single center stated that the center's annual HCV seroconversion rate was $6.8 \%$ despite dedicating separate machines within the dialysis ward for anti-HCV positive patient. After they isolated anti-HCV positive patients in a separate room with dedicated equipment and staff, the annual seroconversion rate dropped to $1 \%$ [40]. A weak point in this study was the reliance on anti-HCV testing for case identification; it is possible that the two cases who seroconverted during the one year of follow up were already infected and in their incubation period at the start of the study.

This demonstrates one obstacle that would arise if we attempt to implement the same isolation strategies of $\mathrm{HBV}$ infected patients to $\mathrm{HCV}$ infected patients. Anti-HCV can be detected in only $80 \%$ of patients within 15 weeks of newly acquired infection. While HCV-RNA can be detected in serum or plasma within 1-2 weeks after exposure, the assay is more expensive than EIA for anti-HCV. In addition, some $\mathrm{HCV}$-infected persons might be only intermittently HCV-RNA positive, particularly those with acute hepatitis $\mathrm{C}$ or with end-stage liver disease caused by hepatitis $\mathrm{C}$.

The second and more important obstacle is logistic. Separating patients on the basis of both their HCV and HBV infection status would be extremely demanding, and even more so if HCV genotypes were taken into consideration. Implementing isolation strategies for $\mathrm{HCV}$ infected patients would either require additional funding to avail isolation facilities or impose restrictions on the choice of dialysis location or treatment modality for $\mathrm{HCV}$ infected patients.

The KDIGO guidelines [34] considered accepting the 'need' for isolation equivalent to accepting the impossibility of full implementation of basic hygienic precautions. The authors considered this a regrettable situation that entails the risk of transmission of pathogens other than HCV. This is not true, and this notion certainly did not prohibit isolation of $\mathrm{HBV}$ infected patients. The serious consequences of acquiring HCV infection on the young dialysis patient, particularly if he/she is being prepared for kidney transplantation, should not be simply disregarded to avoid the burden of isolating HCV infected patients.

To minimize cost, screening with HCV-RNA may be restricted to patients newly admitted to dialysis or recently transferred from another HD center in compliance with the current KDIGO guidelines [31]. Patients infected with different genotypes of HCV may be handled as one group, relying on adherence to infection control measures to prevent super-infection with other genotypes of the virus. In cities where several HD facilities are available, this would simply be a matter of re-arrangement and would not impose severe restrictions on HCV infected patients. The potential of "true" isolation of HCV infected 
patients to minimize nosocomial transmission of $\mathrm{HCV}$ in HD centers is highly significant. What we need is a welldesigned prospective study to evaluate the feasibility and potential benefits of this approach.

\section{Post-exposure prophylaxis}

There is no vaccine against $\mathrm{HCV}$, and no effective form of post-exposure prophylaxis. Strict adherence to infection control measures is the only way to avoid HCV transmission in the health care setting.

Post-exposure management aim at early diagnosis of acute HCV infection, in case it occurs. There is evidence that early antiviral treatment at the stage of acute hepatitis $\mathrm{C}$ is associated with a cure rate exceeding 90\% [41].

The source patient should be tested by EIA for anti-HCV. Immunosuppressed patients (e.g. dialysis patient) may have false negative anti-HCV test results and should always be considered as potentially infected. Persons exposed to an anti-HCV positive, unidentifiable, untested, or immunosuppressed source should be monitored for six months after exposure. Monitoring should include testing by EIA for anti-HCV at baseline, 3 months, and 6 months after exposure. In addition, ALT level should be measured at baseline and then monthly for 4 months after the exposure. A positive anti-HCV test or a rise in ALT level should be followed by HCV-RNA testing. If acute $\mathrm{HCV}$ infection is diagnosed, urgent specialist referral is advised for appropriate management [26].

\section{Summary of the CDC recommendations for control of $H B V$ and $H C V$ in $H D$ centers [6]}

Preventing transmission of infection to HD patients from both recognized and unrecognized sources requires implementation of a comprehensive infection control program. This should include specific infection control practices, routine serologic testing, immunization, surveillance, training and education.

\section{Infection control precautions for all patients}

- Gloves are required whenever caring for a patient or touching the patient's equipment. A supply of clean non-sterile gloves and a discard container should be placed near each dialysis station

- Hands should always be washed after gloves are removed, between patient contacts, and after touching contaminated items. A sufficient number of sinks and soap should be available in the dialysis ward. If the hands are not visibly soiled, an antiseptic hand rub can be used instead.

- Items taken to a patient's dialysis station, including those placed on top of dialysis machines, should be used only for that patient. Otherwise, they should be cleaned and disinfected before returning them to a common clean area or using them for other patients. If the item cannot be disinfected (e.g. adhesive tape), it should be disposed of.

- Medications should be prepared in a room or area separated from the patient treatment area and designated only for medications. Contaminated (i.e. used) supplies, equipment, or biohazard containers should not be stored or handled in areas where medication and clean equipment and supplies are handled.

- Medications should be delivered separately to each patient. Common carts should not be used to distribute medications. If trays are used to deliver medications to a patient, clean them before using for a different patient.

- If a common supply cart is used to store clean supplies in the patient treatment area, this cart should remain at a sufficient distance from patient stations to avoid contamination with blood.

- Intravenous medication vials labeled for single use, including erythropoietin, should not be punctured more than once. Residual medication from two or more vials should not be pooled into a single vial.

- Staff members should wear gowns, face shields, eye wear, or masks to protect themselves and prevent soiling of clothing when performing procedures during which spurting or spattering of blood might occur (e.g., during initiation and termination of dialysis and cleaning of dialyzers). Such protective clothing should be changed if it becomes soiled with blood, body fluids, secretions, or excretions.

- Staff members should not eat, drink or smoke in the dialysis treatment area. Patients can be served meals at their dialysis station. The glasses, dishes, and other utensils should be cleaned in the usual manner.

\section{Cleaning and disinfection}

- Establish written protocols for cleaning and disinfecting surfaces and equipment in the dialysis unit.

- After each patient treatment, clean environmental surfaces at the dialysis station, including the dialysis bed or chair, countertops, and external surfaces of the dialysis machine including containers associated with the prime waste. Use any soap, detergent, or detergent germicide.

- Between uses of medical equipment (e.g. scissors, hemostats, clamps, stethoscopes, blood pressure cuffs), clean and apply a hospital disinfectant. If the item is 
visibly contaminated with blood, use a tuberculocidal disinfectant.

- For a blood spill, immediately clean the area with a cloth soaked with a tuberculocidal disinfectant or a 1:100 dilution of household bleach $(300-600 \mathrm{mg} / \mathrm{L}$ free chlorine). The staff member doing the cleaning should wear gloves, and the cloth should be placed in a bucket or other leak-proof container. After all visible blood is cleaned use a new cloth or towel to apply disinfectant a second time.

- For single-pass machines, perform rinsing and disinfection procedures at the beginning or end of the day. For batch recirculating machines, drain, rinse, and disinfect after each use. Follow the same methods for cleaning and disinfection if a blood leak has occurred.

- In case of possible blood contamination of the internal pressure tubing set and pressure sensing port of the HD machine, the machine must be taken out of service and disinfected using either 1:100 dilution of bleach (300-600 mg/L free chlorine) or a commercially available tuberculocidal germicide before reuse.

- Housekeeping staff members in the dialysis facility should promptly remove soil and potentially infectious waste. All disposable items should be placed in bags thick enough to prevent leakage. These solid medical wastes should be disposed of properly in an incinerator or sanitary landfill, according to local regulations.

\section{Screening and serologic testing}

- The HBV serologic status of all patients should be known before admission to the HD unit. It should be prominently placed in patients' hospital records, and all health-care personnel assigned to these patients should be aware of the patients' serologic status.

- HBsAg testing should be performed monthly for HBV susceptible patients and annually for HBV infected patients. Annual anti-HBs testing should be performed for HBV immune patients.

- Routinely screen all chronic HD patients for HCV infection using EIA for anti-HCV. Repeat screening for anti-HCV negative patients every 6-12 months. Positive anti-HCV results should be confirmed by RT-PCR for HCV-RNA.

- Monthly screen anti-HCV negative patients with ALT levels. Elevated ALT levels should be followed by anti-HCV testing. Persistently abnormal ALT levels in patients who are anti-HCV negative warrant testing for HCV RNA.

- Routine testing of staff members for $\mathrm{HBV}, \mathrm{HCV}$, or HIV infection is not recommended

\section{Hepatitis B vaccination for HD staff members}

- Hepatitis B vaccination is recommended for all staff members working in HD units. Check anti-HBs titer 1-2 months after the last vaccine dose. Staff members with anti-HBs $<10 \mathrm{mIU} / \mathrm{ml}$ should be revaccinated with three additional doses and retested for response.

- Staff members with anti-HBs $<10 \mathrm{mIU} / \mathrm{ml}$ after revaccination should be tested for $\mathrm{HBsAg}$ and counseled accordingly. Non-responders who are HBsAg negative are considered susceptible to HBV infection and will need post-exposure prophylaxis for any probable exposure to HBsAg-positive blood.

- Staff members with documented anti-HBs $\geq 10 \mathrm{mIU} / \mathrm{ml}$ after vaccination are immune to HBV. Booster doses of the vaccine are not necessary, and periodic monitoring of anti-HBs titer is not recommended.

\section{Hepatitis B vaccination for HD patients}

- Hepatitis B vaccination is recommended for all susceptible chronic HD patients (HBsAg negative, anti-HBc negative). Patients with a history of vaccination should have their anti-HBs levels checked when they begin dialysis. If they have anti-HBs titer $<$ $10 \mathrm{mIU} / \mathrm{ml}$, they should be revaccinated with a complete primary series.

- Check anti-HBs titer 1-2 months after the last vaccine dose. Patients with anti-HBs $<10 \mathrm{mIU} / \mathrm{ml}$ should be revaccinated with three additional doses and retested for response. Patients with anti-HBs $<10 \mathrm{mIU} / \mathrm{ml}$ after revaccination are considered susceptible to $\mathrm{HBV}$ infection.

- Patients with anti-HBs $\geq 10 \mathrm{mIU} / \mathrm{ml}$ after vaccination are considered immune to HBV infection. Retest these patients annually for anti-HBs. If anti-HBs declines to less than $10 \mathrm{mIU} / \mathrm{ml}$, administer a booster dose of hepatitis B vaccine. Retesting after the booster dose is not necessary.

\section{Prevention of $\mathrm{HBV}$ infection}

- HBsAg positive patients should be treated in a separate room with dedicated machines, equipment, instruments, supplies, and medications that will not be used by HBV susceptible patients.

- Staff members who are caring for HBsAg positive patients should not care for susceptible patients at the same time, including during the period when dialysis is terminated on one patient and initiated on another.

- Newly opened units should have isolation rooms for the dialysis of HBsAg positive patients. For existing units in which a separate room is not possible, HBsAgpositive patients should undergo dialysis on dedicated 
machines in an area separated from HBV susceptible patients and removed from the mainstream of activity.

- If a machine that has been used on an HBsAg positive patient is needed for an HBV susceptible patient, internal pathways of the machine can be disinfected using conventional protocols and external surfaces cleaned using soap and water or a detergent germicide. Dialyzers should not be reused on HBsAg-positive patients.

- Chronically infected patients should be counseled regarding preventing transmission to others, their household and sexual partners should receive hepatitis $B$ vaccine, and they should be evaluated for the development of chronic liver disease. Annual testing for HBsAg is reasonable to detect the small percentage of HBV infected patients who might lose their HBsAg.

- HBV susceptible patients include HBsAg negative patients who have not yet received hepatitis B vaccine, are in the process of being vaccinated, or have not adequately responded to vaccination.

- Test HBV susceptible patients monthly for HBsAg. This is important for rapid detection of new HBV infection and implementation of isolation procedures before cross-contamination can occur.

- If a seroconversion occurs, review all patients' routine laboratory test and investigate potential sources for infection. This should include the patients' recent history (e.g. blood transfusion, hospitalization, high-risk behavior) as well as unit practices and procedures.

- For patients newly infected with HBV, repeat HBsAg testing and test for anti-HBs after six months. Patients who become HBsAg negative are no longer infectious and can be removed from isolation.

- HBV immune patients include patients who recovered from HBV infection (anti-HBc positive and anti-HBs positive) and patients successfully vaccinated against $\mathrm{HBV}$ who maintain anti-HBs titer $\geq 10 \mathrm{mIU} / \mathrm{ml}$.

- HBV immune patients can undergo dialysis in the same area as HBsAg positive patients, or they can serve as a geographic buffer between HBsAg positive and HBV susceptible patients. Staff members can be assigned to care for both infected and immune patients on the same shift.

\section{Prevention of $\mathrm{HCV}$ infection}

- HCV transmission within the dialysis environment can be prevented by strict adherence to infection control precautions recommended for all HD patients.

- Patients who are anti-HCV positive (or HCV RNA positive) do not have to be isolated from other patients or dialyzed separately on dedicated machines. Anti-HCV positive patients can participate in dialyzer reuse programs.

- HCV infected persons should be evaluated for the development of chronic liver disease. They also should receive information concerning how they can prevent further harm to their liver and prevent transmitting $\mathrm{HCV}$ to others.

- Routinely screen HCV negative patients for anti-HCV every 6 months to monitor transmission within centers and ensure that appropriate precautions are being properly and consistently used.

- Perform monthly ALT testing for anti-HCV negative patients to facilitate timely detection of new infections and help determine when exposure might have occurred. If unexplained ALT elevations are observed repeat anti-HCV testing. If ALT elevations persist despite repeatedly negative anti-HCV, testing for $\mathrm{HCV}$ RNA should be considered.

- When a seroconversion occurs, review all other patients' routine laboratory test results to identify additional cases. Investigate potential sources for infection including review of newly infected patients' recent medical history, history of high-risk behavior, and unit practices and procedures.

- If one or more patients seroconvert during a 6-month period, more frequent (e.g. every 1-3 months) anti-HCV testing of HCV-negative patients is advised for 3-6 months to detect additional infections. If ongoing $\mathrm{HCV}$ transmission is identified, implement control measures based on results of investigation of potential sources for transmission and monitor their effectiveness (e.g. perform more frequent anti-HCV testing for 6-12 months before resuming semiannual testing).

\section{Surveillance for infections and other adverse events}

- Develop and maintain a separate centralized recordkeeping system to record the results of patients' vaccination status and serologic testing (including ALT).

- Maintain records for each patient that include the location of the dialysis station and machine number used for each dialysis session and the names of staff members who connect and disconnect the patient to and from a machine.

\section{Infection control training and education}

- Training and education for all employees at risk for occupational exposure to blood should be provided at least annually, given to new employees before they begin working in the unit, and documented. 
- At a minimum, training should include information on proper hand hygiene, proper use of protective equipment, modes of transmission for bloodborne microorganisms, infection control practices recommended for HD units, proper handling and delivery of patient medications, rationale for isolating HBsAg positive patients, proper methods to clean and disinfect equipment and environmental surfaces, and centralized record keeping to monitor and prevent complications.

\section{References}

1. Johnson DW, Dent H, Yao Q, Tranaeus A, Huang CC, Han DS, Jha V, Wang T, Kawaguchi Y, Qian J. Frequencies of hepatitis $\mathrm{B}$ and $\mathrm{C}$ infections among hemodialysis and peritoneal dialysis patients in Asia-Pacific countries: analysis of registry data. Nephrol Dial Transplant. 2009 May;24(5):1598-603.

2. Scott DR, Wong JK, Spicer TS, Dent H, Mensah FK, McDonald S, Levy MT. Adverse Impact of Hepatitis $\mathrm{C}$ virus infection on renal replacement therapy and renal transplant patients in Australia and New Zealand. Transplantation. 2010 Sep 22.

3. Ridruejo E, Díaz C, Michel MD, Soler Pujol G, Martínez A, Marciano S, Mandó OG, Vilches A. Short and long term outcome of kidney transplanted patients with chronic viral hepatitis B and C. Ann Hepatol. 2010 Jul 1;9(3):271-7.

4. Fabrizi F, Martin P, Dixit V, Kanwal F, Dulai G. HBsAg seropositive status and survival after renal transplantation: meta-analysis of observational studies. Am J Transplant. 2005 Dec;5(12):2913-21.

5. World Health Organization. Hepatitis B virus epidemiology, disease burden, treatment, and current and emerging prevention and control measures. 2002. 76 p. Available from:http://www.who.int/emc.

6. Center for Disease Control and Prevention. Recommendations for preventing transmission of infections among chronic HD patients. MMWR Recomm Rep. 2001 Apr 27;50(RR-5):1-43.

7. Burdick RA, Bragg-Gresham JL, Woods JD, Hedderwick SA, Kurokawa K, Combe C, Saito A, LaBrecque J, Port FK, Young EW. Patterns of hepatitis $\mathrm{B}$ prevalence and seroconversion in hemodialysis units from three continents: the DOPPS. Kidney Int. 2003 Jun;63(6):2222-9.

8. Lanphear BP. Trends and patterns in the transmission of blood borne pathogens to health care workers. Epidemiol Rev. 1994;16(2):437-50

9. Center for Disease Control and Prevention. Recommendations for prevention and control of hepatitis $\mathrm{C}$ virus (HCV) infection and HCV-related chronic disease. Centers for Disease Control and Prevention. MMWR Recomm Rep. 1998 Oct 16;47(RR-19):1-39.

10. Shikata T, Karasawa T, Abe K, Uzawa T, Suzuki H, Oda T, Imai M, Mayumi M, Moritsugu Y. Hepatitis B e antigen and infectivity of hepatitis B virus. J Infect Dis. 1977 Oct;136(4):571-6.

11. Bond WW, Favero MS, Petersen NJ, Gravelle CR, Ebert JW, Maynard JE. Survival of hepatitis B virus after drying and storage for one week. Lancet 1981 Mar;1(8219):550-1

12. Favero MS, Maynard JE, Petersen NJ, Boyer KM, Bond WW, Berquist KR, Szmuness W. Hepatitis-B antigen on environmental surfaces [Letter]. Lancet. 1973 Dec 22;2(7843):1455.

13. Rosenheim Advisory Group. Hepatitis and the treatment of chronic renal failure. London: Department of Health and Social Security, 1972.

14. Center for Disease Control and Prevention. Hepatitis: control measures for hepatitis B in dialysis centers. Atlanta, GA: US Department of Health, Education, and Welfare, Public Health Services, CDC, 1977. HEW publication no. (CDC) 78-8358 (Viral Hepatitis Investigations and Control Series).

15. Ribot S, Rothstein M, Goldblat $M$, Grasso $M$. Duration of hepatitis B surface antigenemia (HBs Ag) in hemodialysis patients. Arch Intern Med. 1979 Feb;139(2):178-80.

16. Hollinger FB and Liang TJ. Hepatitis B virus. In: Knipe DM and Howley PM, editors. Fields Virology. 4th ed. Philadelphia: Lippincott Williams and Wilkins; 2001. p.2971-3036.

17. Onuigbo MA, Nesbit A, Weisenbeck J, Hurlburt J. Hepatitis B surface antigenemia following recombinant Engerix $B$ hepatitis $B$ vaccine in an 81year-old ESRD patient on hemodialysis. Ren Fail. 2010 May;32(4):531-2.

18. Silva AE, McMahon BJ, Parkinson AJ, Sjogren MH, Hoofnagle JH, Di Bisceglie AM. Hepatitis B virus DNA in persons with isolated antibody to hepatitis B core antigen who subsequently received hepatitis B vaccine. Clin Infect Dis. 1998 Apr;26(4):895-7.

19. Aghakhani A, Banifazl M, Kalantar E, Eslamifar A, Ahmadi F, Razeghi E, Atabak S, Amini M, KhademSadegh A, Ramezani A. Occult hepatitis B virus infection in hemodialysis patients with isolated hepatitis B core antibody: a multicenter study. Ther Apher Dial. 2010 Jun;14(3):349-53.

20. Yakaryilmaz F, Gurbuz OA, Guliter S, Mert A, Songur Y, Karakan T, Keles H. Prevalence of occult hepatitis B and hepatitis $\mathrm{C}$ virus infections in Turkish hemodialysis patients. Ren Fail. 2006;28(8):729-35.

21. Fabrizi F, Messa PG, Lunghi G, Aucella F, Bisegna S, Mangano S, Villa M, Barbisoni F, Rusconi E, Martin P. Occult hepatitis B virus infection in dialysis patients: 
a multicentre survey. Aliment Pharmacol Ther. 2005 Jun $1 ; 21(11): 1341-7$.

22. Fraser GM, Ochana N, Fenyves D, Neumann L, Chazan R, Niv Y, Chaimovitch S. Increasing serum creatinine and age reduce the response to hepatitis B vaccine in renal failure patients. J Hepatol. 1994 Sep;21(3):450-4.

23. Miller ER, Alter MJ, Tokars JI. Protective effect of hepatitis B vaccine in chronic HD patients. Am J Kidney Dis. 1999 Feb;33(2):356-60.

24. Mahoney FJ, Stewart K, Hu H, Coleman P, Alter MJ. Progress toward the elimination of hepatitis B virus transmission among health care workers in the United States. Arch Intern Med. 1997 Dec;157(22):2601-5.

25. Cheng CH, Huang CC, Leu ML, Chiang CY, Wu MS, Lai PC. Hepatitis B vaccine in hemodialysis patients with hepatitis C viral infection. Vaccine. 1997 Aug-Sep;15(1213):1353-7.

26. Puro V, De Carli G, Cicalini S, Soldani F, Balslev U, Begovac J, Boaventura L, Campins Martí M, Hernández Navarrete MJ, Kammerlander R, Larsen C, Lot F, Lunding S, Marcus U, Payne L, Pereira AA, Thomas T, Ippolito G; European Occupational Post-Exposure Prophylaxis Study Group. European recommendations for the management of healthcare workers occupationally exposed to hepatitis B virus and hepatitis $\mathrm{C}$ virus. Euro Surveill. 2005 Oct;10(10):260-4.

27. Wasley A, Alter MJ. Epidemiology of hepatitis C: geographic differences and temporal trends. Semin Liver Dis. 2000 ; 20(1): 1-16

28. Fissell RB, Bragg-Gresham JL, Woods JD, Jadoul M, Gillespie B, Hedderwick SA, Rayner HC, Greenwood RN, Akiba T, Young EW. Patterns of hepatitis C prevalence and seroconversion in hemodialysis units from three continents: the DOPPS. Kidney Int. 2004 Jun;65(6):2335-42.

29. Shepard CW, Finelli L, Alter MJ. Global epidemiology of hepatitis C virus infection. Lancet Infect Dis. 2005 Sep;5(9): 558-67

30. Cendoroglo Neto M, Draibe SA, Silva AE, Ferraz ML, Granato C, Pereira CA, Sesso RC, Gaspar AM, Ajzen H. Incidence of and risk factors for hepatitis $\mathrm{B}$ virus and hepatitis $\mathrm{C}$ virus infection among haemodialysis and CAPD patients: evidence for environmental transmission. Nephrol Dial Transplant. 1995;10(2):240-6.

31. Kidney Disease: Improving Global Outcomes (KDIGO). KDIGO clinical practice guidelines for the prevention, diagnosis, evaluation, and treatment of hepatitis $\mathrm{C}$ in chronic kidney disease. Kidney Int Suppl. 2008 Apr;(109):S1-99.

32. Alter HJ, Seeff LB. Recovery, persistance, and sequelae in hepatitis $C$ virus infection: a perspective on long-term outcome. Semin Liver Dis. 2000;20(1):17-35.
33. Pol S, Romeo R, Zins B, Driss F, Lebkiri B, Carnot $\mathrm{F}$, Berthelot $\mathrm{P}$, Bréchot $\mathrm{C}$. Hepatitis $\mathrm{C}$ virus RNA in anti-HCV positive hemodialyzed patients: significance and therapeutic implications. Kidney Int. 1993 Nov;44(5):1097-100.

34. Alter HJ, Jett BW, Polito AJ, et al. Analysis of the role of hepatitis $\mathrm{C}$ virus in transfusion-associated hepatitis. In: Hollinger FB, Lemon SM, Margolis H, eds. Viral hepatitis and liver disease. Baltimore (MD): Williams and Williams; 1991. p. 396-402.

35. Taskapan H, Oymak O, Dogukan A, Utas C. Patient to patient transmission of hepatitis $\mathrm{C}$ virus in hemodialysis units. Clin Nephrol. 2001 Jun;55(6):477-81.

36. Shamshirsaz AA, Kamgar M, Bekheirnia MR, Ayazi F, Hashemi SR, Bouzari N, Habibzadeh MR, Pourzahedgilani N, Broumand V, Shamshirsaz AH, Moradi M, Borghei M, Haghighi NN, Broumand B. The role of hemodialysis machines dedication in reducing Hepatitis $\mathrm{C}$ transmission in the dialysis setting in Iran: a multicenter prospective interventional study. BMC Nephrol. 2004 Oct 7;5(1):13.

37. Valtuille R, Moretto H, Lef L, Rendo P, Fernández JL. Decline of high hepatitis $\mathrm{C}$ virus prevalence in a hemodialysis unit with no isolation measures during a 6-year follow-up. Clin Nephrol. 2002 May;57(5):371-5.

38. JadoulM, CornuC, van Ypersele deStrihouC.Universal precautions prevent hepatitis $\mathrm{C}$ virus transmission: a 54 month follow-up of the Belgian Multicenter Study. The Universitaires Cliniques St-Luc (UCL) Collaborative Group. Kidney Int. 1998 Apr;53(4):1022-5.

39. Petrosillo N, Gilli P, Serraino D, Dentico P, Mele A, Ragni P, Puro V, Casalino C, Ippolito G. Prevalence of infected patients and understaffing have a role in hepatitis $\mathrm{C}$ virus transmission in dialysis. Am J Kidney Dis. 2001 May;37(5):1004-10.

40. Saxena AK, Panhotra BR, Sundaram DS, Naguib M, Venkateshappa CK, Uzzaman W, Mulhim KA. Impact of dedicated space, dialysis equipment, and nursing staff on the transmission of hepatitis $\mathrm{C}$ virus in a hemodialysis unit of the Middle East.Am J Infect Control. 2003 Feb;31(1):26-33.

41. Jaeckel E, Cornberg M, Wedemeyer H, Santantonio T, Mayer J, Zankel M, Pastore G, Dietrich M, Trautwein C, Manns MP; German Acute Hepatitis C Therapy Group. Treatment of acute hepatitis $\mathrm{C}$ with interferon alfa-2b. N Engl J Med. 2001 Nov 15;345(20):1452-7. 